\title{
intuitio
}

\section{A IMAGEM DO BRASILEIRO DO PONTO DE VISTA DE UM IMIGRANTE DA EUROPA: UMA ANÁLISE FENOMENOLÓGICA A PARTIR DE VILÉM FLUSSER}

\author{
BRAZILIAN'S IMAGE ACCORDING TO A EUROPEAN \\ IMMIGRANT: A PHENOMENOLOGICAL ANALYSIS FROM \\ VILÉM FLUSSER'S PERSPECTIVE
}

Jair Inácio Tauchen ${ }^{1}$

\begin{abstract}
Resumo: Vilém-Flusser emigrou da Europa para o Brasil. Trinta anos depois, sentindo-se brasileiro, ele deixou o Brasil e foi para a Europa, atestando sua permanente condição estrangeira. Este ensaio pretende ser uma descrição fenomenológica da natureza e dos habitantes do Brasil do ponto de vista de um imigrante. Nosso objetivo é analisar o significado de ser brasileiro e estar no Brasil de acordo com a Fenomenologia do Brasileiro de Flusser. Como imigrante, Flusser não conseguia se envolver completamente na realidade brasileira. Apesar de se sentir desorientado e confuso, Flusser sempre procurou sua identidade. Mas, devido ao seu diagnóstico superficial da natureza e dos habitantes do país, sua análise fenomenológica está, em parte, comprometida.
\end{abstract}

Palavras-chaves: imigrante. Estrangeiro. Identidade. Brasileiro. Fenomenologia.

Abstract: Vilém-Flusser emigrated from Europe to Brazil. Thirty years later, feeling Brazilian, he left Brazil and went to Europe, attesting his permanent foreign condition. This essay aims to be a phenomenological description of Brazil's nature and inhabitants from the point of view of an immigrant. Our goal is to analyze the meaning of being

\footnotetext{
1 Pontifícia Universidade Católica do Rio Grande do Sul (PUCRS). ORCID: http://orcid.org/ o000-0002-1974-016X. E-Mail: jairtauchen@gmail.com
} 
Brazilian and being in Brazil according to Flusser's Fenomenologia do Brasileiro. As an immigrant, Flusser could not completely engage himself in Brazil's reality. Despite feeling disoriented and confused, Flusser always looked for his identity. But, because of his superficial diagnosis of the country's nature and inhabitants, his phenomenological analysis is, in part, jeopardized.

Keywords: immigrant. Foreigner. Identity. Brazilian. Phenomenology.

\section{INTRODUÇÃO}

Flusser foi um brasileiro que não nasceu no Brasil. Escreveu a Fenomenologia do brasileiro em português e alemão, publicado primeiro em alemão sob o título: Brasilien oder die Suche nach dem neuen Menschen: für eine Phänomenologie der Unterentwicklung ("Brasil, ou a procura de um novo homem: por uma fenomenologia do subdesenvolvimento"), pela Bollmann Verlag, em 1994. Embora o texto tenha sido escrito muito antes, conduz o leitor para uma ampla abertura das perspectivas dos fenômenos. Pela importância que representa a obra, ela será utilizada como referência para esta pesquisa, sobretudo, o tema que trata do imigrante brasileiro e da natureza brasileira sob o ponto de vista do imigrante europeu. Todavia, é recomendável uma breve suspensão do juízo - no sentido de julgamento e crença - a fim de compreender o fenômeno sob uma perspectiva diferente, irônica, amargurada e até mesmo exagerada. ${ }^{2}$

O estilo jocoso, irônico e exagerado que Flusser utiliza ao se expressar e escrever pode irritar algumas pessoas, mas é aí que reside a sua força. As imprecisões no processo de descrição não devem ser vistas como um problema, mas como uma oportunidade de se aproximar do seu modo de pensar. Para ele, a vivência na ausência de fundamento, daquilo que ela chama de "sem chão", é tão importante quanto a construção da cultura que dela advém.

A excentricidade de Flusser e a sensação de não-pertencimento fazem parte do seu universo, uma característica própria de se reconhecer e se relacionar com este ambiente simbólico de construção ficcional da realidade.

2 Este aspecto também pode ser observado na sua autobiografia filosófica: Bodenlos. 
É neste contexto que se deve distinguir a sua fenomenologia e, no caso específico, uma fenomenologia especulativa de construção da realidade pela ficção. Em outros termos, a fenomenologia flusseriana tem como objetivo a construção de modelos de compreensão do conhecimento e da realidade.

O que significa para Flusser estar no contexto "Brasil"? Na fuga de Praga para a Inglaterra a fim de sobreviver a perseguição nazista, e posteriormente ao Brasil, ao desembarcar no Porto do Rio de Janeiro, sentiu-se apenas em algum lugar. Esse sentimento de desolação pode ser evidenciado no seu desabafo por ocasião da fuga: "era necessário emigrar para territórios inteiramente exóticos e fantásticos, nos quais a gente era automaticamente sombra. Para territórios inteiramente fora da realidade. Para Tailândia ou o Brasil, por exemplo."3 Apesar da necessidade de emigrar para um novo território, a opção pelo "exótico" Brasil, aliado à falta de sentido que isso provocava, está bem inscrito no título da sua autobiografia intelectual: Bodenlos, que justamente significa "sem chão", "sem fundamento". A partir dessa dimensão do lugar, reconhecendo em si o ente perdido, desorientado, angustiado em busca de nova identidade, configura um novo mapa do Brasil e desenha a sua fenomenologia do brasileiro, a saber: uma descrição fenomenológica de um Brasil vivido.

Sua intenção consiste em oferecer um ponto de vista bastante estreito ao apresentar a perspectiva de um "intelectual brasileiro imigrado da Europa" com o propósito de se reconhecer e se orientar neste novo ambiente. Isso está claro ao relatar o objetivo do ensaio: "será uma imagem do brasileiro do ponto de vista de um imigrante da Europa. [...] Como descrição de um país e seus habitantes."4 Portanto, o intento é apresentar

\footnotetext{
3 FLUSSER, Vilém. Bodenlos: uma autobiografia filosófica, p. 46.

4 FLUSSER, Vilém. Fenomenologia do brasileiro: em busca de um novo homem, p. 38.
} 
uma imagem que sirva de orientação ao ocidental em geral e, sobretudo, a si próprio, ao intelectual burguês do Ocidente ${ }^{5}$, como se denominava. Chama atenção a biografia de Flusser. ${ }^{6}$ Foi alguém que emigrou da Europa para o Brasil; depois de mais de trinta anos, sentindo-se brasileiro, emigrou do Brasil para a Europa, o que demonstra sua permanente condição de estrangeiro.7 Em função disso se sente essencialmente perdido e deprimido, e para se encontrar e se orientar precisa tomar a decisão de abrir caminho, ou nas suas palavras, "abrir sua própria picada" na rota Brasil. A sensação de desorientação tornou praticamente insuportável a sua existência por um longo período. ${ }^{8}$ A fim de encontrar-se consigo mesmo foi preciso retroceder para compreender a nova realidade e, finalmente, agir decididamente.

\footnotetext{
5 Nas palavras de Flusser, "o presente ensaio é um depoimento da nossa situação do ponto de vista de um imigrante brasileiro. Como depoimento, procura não apenas dar-se conta a si mesmo e aos outros da situação na qual todos estamos, mas também encontrar caminhos e saídas. Em tal depoimento aparece, expressamente, apenas o mundo vital do autor, a saber, o Brasil, mas também, implicitamente a situação geral de nós todos. O depoimento procura ser honesto, mas sabe que a honestidade é um ideal de muito difícil alcance. Portanto o depoimento se oferece assim: enquanto ensaio, não obra - e assim quer ser lido". Cf. FLUSSER, Vilém. Fenomenologia do brasileiro: em busca de um novo homem, p. 38 .

6 Na sua concepção, imigrante é a pessoa "que abandonou uma situação para integrar-se em outra, portanto pessoa que se abre a uma nova situação a fim de alterar-se e a fim de alterá-la. A imigração é um processo dialético, no qual o imigrante recebe o impacto do ambiente e o ambiente do imigrante. $O$ resultado do processo, se coroado com êxito, é a alteração de ambos os fatores." Cf. FLUSSER, Vilém. Fenomenologia do brasileiro: em busca de um novo homem, p. 45.

7 Flusser demonstra sua "estrangeiridade" no trecho do ensaio $O$ cedro no parque: "Estrangeiro (e estranho) é quem firma seu próprio ser no mundo que o cerca. Assim, dá sentido ao mundo, e de certa maneira o domina. Mas o domina tragicamente: não se integra. O cedro é estrangeiro no meu parque. Eu sou estrangeiro na França. O homem é estrangeiro no mundo." FLUSSER, Vilém. Natural:mente, p. 52.

8 O encontro com o passado dificulta o progresso. A desorientação é tal que convive com a hipótese do suicídio, como relata na sua autobiografia: "A pergunta 'por que a gente não se matou?' recebe duas respostas. A primeira diz que a gente não se matou por covardia, porque temia as dores da morte e porque temia a sujeira de ser objeto nojento. A outra resposta diz que a gente não se matou porque sentia coragem. Porque acreditava obscuramente que tinha ainda tarefa a cumprir, embora ignorasse qual a tarefa. Pode perfeitamente ser que ambas as respostas fossem verdadeiras, embora se contradissessem. O fato é que a gente nem se matou nem deixou de brincar constantemente com a possibilidade da nossa morte. A possibilidade de matar-se hoje, e de não ter que enfrentar o amanhã, tornou viável o amanhã, e o fazia diariamente". Cf. FLUSSER, Vilém. Bodenlos: uma autobiografia filosófica, p. 59-60.
} 


\section{O PONTO DE VISTA DO IMIGRANTE BRASILEIRO}

O tema da "imigração" abordado por Flusser é importante por manifestar o seu ponto de vista sobre a questão. Reconhece que o ambiente brasileiro é de fácil penetração ao imigrante, porém de difícil integração: "é fácil viver-se no Brasil enquanto imigrante, e desesperadamente difícil integrar-se nele" ${ }^{\prime \prime}$, diz o imigrante. Essa assertiva, no caso específico brasileiro, tem relação direta com a personalidade, a tradição, o grau de cultura e os preconceitos do imigrante, pois, quanto mais forte for, mais demorado e penoso será o processo. Contudo, de outro modo, quanto melhor estruturado e maleável o ambiente, mais fácil a alteração ${ }^{10}$.

Afinal, o que significa ser brasileiro para Flusser? Ser brasileiro implica sintetizar dentro de si e no mundo em que vive tendências históricas e não-históricas, a fim de obter a síntese criativa; significa ser homem e dar sentido à sua vida; significa ser homem que supera a história e a transforma em lugar no qual a história é absorvida. Para Flusser, a "essência brasileira não é uma maneira de ser, mas uma maneira de buscar. O Brasil não é perfeito (no sentido de 'realizado' e, portanto, 'passado'), mas é assumido (no sentido de, olhando para a frente, arriscado e apenas esboçado)."11 $\mathrm{A}$ sua virtualidade articula-se na população rural desenraizada e no proletariado alienado. A burguesia que aspira o progresso será peça chave para entender o futuro; no campo revolucionário a juventude acadêmica "dirá que o ponto de vista aqui defendido é reacionário e desprezível"; no campo conservador, que detém o poder, "dirá que se trata de ponto de

\footnotetext{
9 FLUSSER, Vilém. Fenomenologia do brasileiro: em busca de um novo homem, p. 45.

10 Mais adiante Flusser reformula o comentário de que "viver como imigrante no Brasil é fácil, mas difícil é integrar-se". A nova constatação é que "para pessoas inteligentes é fácil viver no Brasil, já que não encontram obstáculo, desde que se decidam romper com sua origem" (grifo nosso). Mesmo essa condição não a transforma em brasileiro, pois é tarefa para uma vida inteira. Cf. FLUSSER, Vilém. Fenomenologia do brasileiro: em busca de um novo homem, p. 47.

$"$ FLUSSER, Vilém. Fenomenologia do brasileiro: em busca de um novo homem, p. 54.
} 
vista estrangeiro e, tomado de recém-adquirido chauvinismo, recusará o ponto de vista rejeitando-o como um imiscuir-se indevido."12

$\mathrm{O}$ anseio da burguesia pelo progresso se explica pela enorme e intolerável miséria em que vive grande parte da população e que somente pode ser aplacada pelo desenvolvimento econômico e tecnológico; pelas ideologias europeias do século XIX, "que fazem crer aos burgueses que a única saída para o país são as sociedades neocapitalistas"; que em razão da dimensão geográfica e o elevado contingente populacional, os burgueses acreditam, "que alcançada a história, o Brasil poderá dela participar definitivamente." No entanto, Flusser entende que é muito difícil a leitura e compreensão da realidade para os burgueses. Reconhece que a burguesia conservadora empenha enorme esforço no desenvolvimento econômico, mesmo tendo algum êxito, está longe de tornar o Brasil uma potência.

Ao abordar o aspecto da colonização, entende que o Brasil mesmo tendo Portugal por mãe-pátria europeia, não ocorreu o mesmo grau de importância que a Inglaterra desempenhou na colonização dos Estados Unidos. Assim, na sua visão, a população brasileira não descende, como a americana, "de pessoas que conquistaram um grande território em nome da Europa e aniquilaram os indígenas ou empurraram seus restos insignificantes para um canto."13 Mas, de pessoas que perderam os laços com a Europa, que travaram longa luta com a "terrível" natureza, que se misturaram com a população indígena, decaindo a um estágio pouco superior aos indígenas, isto é, para um "secundário primitivismo". Na compreensão de Flusser, por perder sua historicidade, a pessoa não se sente mais sujeito da história, mas um indivíduo explorado, manipulado e sofredor da história.

Ainda sobre a colonização do Brasil pelos portugueses ${ }^{14}$, acreditava que os objetivos iniciais eram o enriquecimento de Portugal e a diminuição

\footnotetext{
12 FLUSSER, Vilém. Fenomenologia do brasileiro: em busca de um novo homem, p. 55.

13 FLUSSER, Vilém. Fenomenologia do brasileiro: em busca de um novo homem, p. 49.

14 Flusser faz uma comparação detalhada entre a colonização dos Estados Unidos e o Brasil, tecendo elogios à formação da população e cultura dos americanos. Como a proposta é analisar o que Flusser entende por "brasileiro", o comentário sobre a colonização americana não será desenvolvido.
} 
da superpopulação portuguesa. No processo de colonização, ao mesmo tempo que o Brasil recebeu uma orla de fracassados e escravos, também chegou uma pequena quantidade de perseguidos e contestadores interessados na vastidão das terras brasileiras. Portanto, os colonizadores europeus não tinham o interesse de fazer do Brasil uma segunda Europa. O principal interesse era explorar as riquezas e o seu território. Todos esses imigrantes nunca foram bem recebidos, apenas tolerados, conclui Flusser.

Ao contrário do que Flusser pensava, os primeiros colonos enviados para o Brasil não eram apenas ladrões, assassinos ou prostitutas. A grande parte era composta por pobres que acompanhavam os nobres para auxiliar na construção de engenhos e trabalhar no cultivo da cana-de-açúcar. Apenas uma pequena parcela era constituída de "criminosos", geralmente indivíduos perseguidos pela Igreja por "falta moral" ou por cometerem pequenos delitos. Logo, fica evidente o equívoco de Flusser, porque a maior parte dos colonos que vieram para o Brasil não foram apenas os degradados, fracassados e escravos. O que realmente promoveu o desenvolvimento da colonização foi a vinda das famílias abastadas de Portugal que se estabeleceram nas zonas mais ricas, como as cidades de Pernambuco e Bahia.

Em nova tentativa de desvendar a essência do brasileiro, Flusser discorre sobre o mito das "três raças tristes", cuja síntese encontra-se na escravização do negro, na perseguição e abuso do índio e pela presença europeia (portuguesa). $O$ aspecto a ser considerado das três raças, é a questão "triste". Aqui Flusser se refere ao português, ao negro e ao índio "que foram desprezados pela história e, quiçá, por isso são 'tristes". O que os une são dois elementos: "ou foram eliminados da história, ou nunca a penetraram". Ressalta que os processos que ocorrem no Brasil acontecem à margem da história e da consciência do brasileiro.

Essa questão é considerada pelos críticos como um "mito" porque procura idealizar a miscigenação brasileira, porém minimizando a violência da dominação colonialista e equilibrando as três raças, quando, na verdade, existe um desiquilíbrio estrutural entre elas. Outro argumento a considerar é que teóricos como Sérgio Buarque de Holanda criticam o conceito de 
raça como definidor de cultura. Outro ponto contestado nas afirmações de Flusser é que ele subentende "indígena" e "africano" enquanto categorias homogêneas, quando se sabe que cada uma dessas raças é composta por diferentes etnias. Mesmo que o "mito das três raças" vise caracterizar a formação da sociedade brasileira, não se pode deixar de destacar que, embora o Brasil seja composto por uma grande miscigenação, a convivência entre si das diferentes raças brasileiras é marcada pelo preconceito e conflito.

Neste aspecto Flusser está alinhado com a realidade brasileira. Esta combinação está no centro da essência brasileira, pois o Brasil reconhecidamente é o país das misturas em todos os níveis. Salienta que um dos resultados positivos das misturas raciais é a beleza e, no caso brasileiro, a graça e a elegância da mulher que sempre é elogiada, mas nunca o suficiente. O próprio Flusser se rende aos seus encantos,

[...] em parte alguma (isto pode ser afirmado sem exagero), a feminilidade se apresenta em formas tão perfeitas e sedutoras. Parece que a mistura de raças conseguiu alcançar uma síntese graças à qual o especificamente racial cede ao genericamente humano em novo nível (no caso: ao genericamente feminino). Não pode haver argumento melhor para reforçar que o Brasil seja contra o racismo. ${ }^{15}$

O fenômeno da imigração é um movimento importante na história das civilizações e, sobretudo, na contemporaneidade. Por ocupar esse lugar de destaque na história, Flusser entende que a literatura que aborda o tema da imigração é muito reduzida considerando o impacto causado aos imigrantes, especialmente no seu caso específico de intelectual imigrante. Na sua concepção, esse indivíduo seria o mais indicado a ser analisado por ter a capacidade de expressar sua condição migratória e a possibilidade de desvendar a estrutura de sua vida. Nesse caso, analisar o background

15 FLUSSER, Vilém. Fenomenologia do brasileiro: em busca de um novo homem, p. 52. 
sociocultural, a posição geográfica, o território e o momento histórico em que ocorreu o processo imigratório. Do imigrante Flusser é demandado que se liberte de todos os preconceitos que abarcam a realidade a fim de transparecer o Brasil da seguinte maneira:

O primeiro contato se dá com a massa urbana heterogênea e quase amorfa. É verdade que a massa fala uma única língua (o português), e isto parece dar-lhe estrutura. Mas o ouvido atento descobre que essa língua não é infraestrutura (como no caso das sociedades europeias), mas que forma um teto a reunir a massa, qual esperanto ou koiné, debaixo do qual pulsam inúmeras outras línguas que se refletem no próprio português para poder penetrar a massa e integrar-se nela. ${ }^{16}$

Apesar das grandes diferenças regionais, manteve-se a mesma unidade linguística. O povo brasileiro é resultante da mistura de europeus, africanos e indígenas, cuja união resultou uma cultura peculiar que Flusser não conseguiu se integrar e se adaptar. Muito provavelmente, ao penetrar na massa, ele se deparou com as decadências da "provincialização e primitivização" que remetem à sua origem.

O proletário e o subproletário dessa sociedade é originário da população rural brasileira, constituída em grande parte de descendentes de escravos. A imigração interna dessa população favoreceu o crescimento desorganizado das cidades, tornando esses humanos desenraizados e alienados, com enorme dificuldade de se adaptar à vida nesses centros. Dessa particularidade emerge a pequena e média burguesia que dará origem a uma elite responsável pela camada intelectual e acadêmica na qual Flusser passa a fazer parte, mas com grande dificuldade de encon-

${ }^{16}$ FLUSSER, Vilém. Fenomenologia do brasileiro: em busca de um novo homem, p. 40. 
trar-se consigo mesmo. ${ }^{17}$ Considera sua estrutura atrasada, ignorante, um "joguete nas mãos das forças superiores."

A próxima análise visa o homem rural que forma a base da população. Para Flusser, todo esforço em captar a realidade parece inútil, mesmo que parte dessa população seja constituída de europeus (portugueses), pois, no decorrer do tempo, perderam a ligação com o Ocidente, seja pela solidão, pelo clima difícil ou pela natureza cruel que os envolve. Flusser reporta essa situação de abandono e ignorância ao descrever: "a população rural não é nem 'nova' nem 'jovem' (embora seja constituída em grande parte por crianças), mas é tão antiga e imemorial quanto o é o neolítico no qual vive mentalmente. ${ }^{18}$ Ou seja, uma massa de "europeu decadente" atrasada, ignorante e de fácil manipulação pela elite.

Flusser se refere ao brasileiro como um europeu decadente. Na sua concepção os brasileiros "não tomaram posse nem da sua terra nem de si mesmos, mas flutuam, tomados de um atordoamento secular chamado 'saudade', nas suas imensas planícies, quais destroços nas ondas." ${ }^{19}$ Esse indivíduo não se constituiu proprietário da terra e tem muita dificuldade com o cultivo, pois é extremamente atrasado. Também, não conseguiu fincar raízes nessa terra e a abandona diante das catástrofes naturais. São indivíduos "alheios a si mesmos e à sua terra, e olham espantados o mundo, inclusive o imigrante." ${ }^{20}$

Todavia, Flusser reconhece que é perfeitamente possível ter se enganado sobre o que disse ao interpretar os fenômenos do ponto de vista do

\footnotetext{
${ }_{17}$ A mencionada elite é constituída de homens perdidos, desenraizados que não se descobrem nem como indivíduos e nem como grupos. Para Flusser, "finalmente o imigrante descobre na massa urbana um ínfimo grupo de noveaux-riches que vegeta em luxo oriental sem jamais sequer contemplar o papel de elite que poderia desempenhar estruturalmente. Inteiramente alienado de si mesmo e de sua sociedade, tal grupo aparece ao imigrante apenas em forma de palacetes kitsch, de apartamentos opulentos e de notícias 'sociais' na imprensa de segunda categoria; serve apenas para salientar, por contraste, a miséria das cidades”. Cf. FLUSSER, Vilém. Fenomenologia do brasileiro: em busca de um novo homem, p. 42.

18 FLUSSER, Vilém. Fenomenologia do brasileiro: em busca de um novo homem, p. 42.

19 FLUSSER, Vilém. Fenomenologia do brasileiro: em busca de um novo homem, p. 43.

20 FLUSSER, Vilém. Fenomenologia do brasileiro: em busca de um novo homem, p. 43.
} 
imigrante. Reconhece no caboclo brasileiro, tanto aquele do mato como o que transita pela cidade, que sofre todo tipo de provação e doença, uma fonte promissora para uma cultura do futuro. Uma cultura ancorada no coração desse caboclo que se manifesta em "cortesia quase cavalheiresca". O que parece ser uma submissão desse indivíduo, esconde no seu íntimo o orgulho e dignidade, dificilmente percebido por um "civilizado".

Diante disso, Flusser se sente incapaz de compreender "essa gente", sendo necessário recorrer a elementos literários como Guimarães Rosa e Euclides da Cunha. Além de incapaz, não se sente motivado para se engajar a essa população. Na sua visão é um povo que manifesta costumes arcaicos como, por exemplo, berrar em alto-falantes para comunicar algo alheio a essa gente. Questiona o fato de as pessoas ficarem "paradas na esquina olhando o nada, o ficar acocorado nos calcanhares, [...] as crianças sujas brincando com vira-latas em chão batido das casas de lama." ${ }^{21}$ Também se manifesta na precariedade das estradas que ligam as colônias rurais, na decadência dos latifúndios improdutivos e no próprio Estado que não toma iniciativa.

$O$ encontro seguinte de Flusser ocorre com as pessoas que considera "verdadeiramente brasileiras". No caso, elas se constituem de uma minoria de pseudoaristocratas descendentes dos colonizadores do século XVI, com um nível intelectual mais elevado. Reconhecidamente é uma sociedade fechada que deverá servir de modelo na tentativa de formar no futuro uma mentalidade brasileira. É um pequeno grupo fechado com influência decrescente que vive nas cidades, mas tem seu fundamento na propriedade rural. Todavia, é importante para a compreensão do país, pois, segundo Flusser, essa minoria era a representação da sociedade, foi responsável pela criação e desenvolvimento da cultura e que detinha o poder político. Portanto, um grupo imigrante no próprio país, diferente do imigrante europeu, mas que não admite tal condição. Uma elite que luta por um Brasil, mas "que existe apenas na sua memória e nas obras culturais por ele criadas."

${ }^{21}$ FLUSSER, Vilém. Fenomenologia do brasileiro: em busca de um novo homem, p. 43 


\section{A NATUREZA BRASILEIRA SOB O PONTO DE VISTA DO IMIGRANTE EUROPEU}

A impressão que Flusser tem sobre a natureza brasileira é carregada de acidez e de ranço que no primeiro momento impressiona. É importante alertar que no momento da descrição ele se encontrava em desespero e profundamente desorientado perante a dificuldade de engajar-se na sociedade brasileira. Para Flusser, tudo é problema, inclusive a natureza, que não passa de algo que causa profundo transtorno. Na sua opinião o fato de o burguês brasileiro afirmar que ama a paisagem, que considera o Brasil um "país abençoado pelas belezas naturais, onde canta o sabiá e onde os prados têm mais flores", tudo não passa de uma visão ideológica romântica, "conversa fiada".

Até pode ocorrer que algum habitante ao vivenciar esteticamente a paisagem a ache bela. Assim como, o turista que vê a estrutura da paisagem e simplesmente emite um juízo de bonito ou feio. Na visão de Flusser o turista no Brasil vê a paisagem como monótona, "mais ou menos 'feia"; sobre o fato do habitante reconhecer a beleza dos prados com suas flores extremamente belas, Flusser acha isso um engano porque, na sua concepção, existem pouco prados no Brasil e eles praticamente não têm flores. Talvez em função disso, de ter poucas flores, é que o habitante repara nelas, diz ele.

Flusser descreve a impressão estética que o Brasil causa ao imigrante "(inautenticamente transformado em turista)." ${ }^{22}$ Pela impressionante des-

\footnotetext{
22 Em Bodenlos, Flusser faz uma descrição muito parecida sobre o seu ponto de vista a respeito da natureza brasileira. O contato de forma objetiva foi relatado como: "um imenso planalto levemente ondulado, sem acidentes notáveis, e coberto de vegetação relativamente baixa, mas esporadicamente densa, forma o núcleo da natureza brasileira. Tal planalto se inclina para o oeste em direção aos enormes pântanos, em busca dos quais corre a maioria dos rios que o cortam, e cai para leste em direção ao oceano por dois degraus abruptos, a serra da Mantiqueira e a serra do Mar: portanto dá as costas ao mar e encara o centro do Continente. Duas cores predominam no planalto: o roxo avermelhado de uma terra que tende a levantar-se em poeira, e o verde escuro de uma vegetação perene. O clima é úmido, continental e subtropical na parte sulina do planalto, e tende a tornar-se seco, continental e tropical quanto mais a gente avança rumo ao norte. A pressão é quase sempre alta, de forma que a sensação de opressão e depressão predomina, interrompida apenas por noites claras e certas manhãs límpidas libertadoras. A luz solar é muito forte, e mata todas as cores, salvo as mais berrantes. A vida animal é surpreendentemente rara, com exceção de insetos e répteis. Quase não há flores, mas há
} 
crição, fica aparente o desconforto que sente com o ambiente e o descontentamento pela natureza brasileira. Na sequência avança, afirmando que o país promete muito e cumpre quase nada do prometido. Por exemplo, as praias brasileiras, tanto as nordestinas com suas palmeiras e as do Sul com as serras, com areia morna e macia, com seus pescadores ingênuos e a-históricos formam "efetivamente paraísos". Mas, a decepção do turista imediatamente aparece ao constatar a "inacreditável monotonia da natureza brasileira":

A pressão atmosférica é uniformemente alta e amortece os movimentos; o conteúdo da água no ar, constantemente alto, provoca suor; no Nordeste só há verão e dias e noites são de duração constante; no Sul é problemática a distinção entre verão e primavera (mas primavera que não representa um despertar do inverno); as praias se estendem em linhas retas por quilômetros, e a costa brasileira prima por falta de articulação (se comparada, obviamente, com a europeia). 0 alheamento brasileiro da natureza favorece que nas praias de determinados lugares surjam amontoados de prédios altos (espécie de favelas da pequena burguesia), e são estes lugares horríveis os únicos realmente acessíveis ao turista. Outra consequência de tal alheamento é o fato de o turista poder degustar nos restaurantes das praias cervejas argentinas, uvas californianas e bacalhau português, mas terá dificuldade em obter os peixes da própria praia. ${ }^{23}$

A pujante natureza brasileira revela-se para Flusser como incrivelmente monótona e considera que isso possa ser a razão para o desmatamento: "o fundamental alheamento que o brasileiro sente pela natureza faz com que a procure derrubar (em vez de salientá-la artificialmente, como faz

árvores floridas. O impacto que o planalto causa pode assim ser resumido: senilidade pacífica, meiga e deprimente". Cf. FLUSSER, Vilém. Bodenlos: uma autobiografia filosófica, p. 79-80.

23 FLUSSER, Vilém. Fenomenologia do brasileiro: em busca de um novo homem, p. 63. 
o europeu para o deleite do turista)." ${ }^{24}$ Ainda na sua opinião, ao se afastar da praia em direção ao interior, a coisa "se torna muito mais terrível", querendo afirmar que o ambiente sempre pode piorar. A descrição do ambiente relata uma paisagem inarticulada com no "máximo cinco tipos de vegetação", sendo a maioria rasteira e infestada de insetos. Mesmo tendo muita boa vontade para entender a frustração de Flusser, a realidade brasileira, como país continental, não condiz com o ponto de vista dele.

O turista ao percorrer o caminho o faz a "cem quilômetros por hora" para escapar do tédio e vencer as longas distâncias que são "desumanamente extensas". Além disso, afirma que não existem lagos, riachos, vales escondidos, picos majestosos, geleiras, vulcões. A exceção na paisagem são os acidentes geográficos isolados como a cachoeira das Sete Quedas, mas "que continuam tediosos devido ao gigantismo e isolamento." ${ }^{25} \mathrm{Na}$ sua visão é uma desolação completa, pois não há mamíferos visíveis, poucos pássaros, porém muitos urubus, e a fauna é representada sobretudo por formigas, moscas e mosquitos. A exceção são as serras próximas ao Rio, São Paulo e Porto Alegre; “e é lá que se refugia o imigrante sedento de 'natureza', se não consegue viajar para a Europa. Mas tais ilhas podem ser desprezadas, já que são o que há de menos brasileiro na paisagem brasileira." ${ }^{26}$

Essa visão de Flusser sobre a natureza local pode levar o brasileiro nato a se espantar ou se indignar pela maneira áspera, irônica e exagerada que utiliza, ainda que desde o princípio tenha alertado que o exagero faz parte do seu método. Por exemplo, o brasileiro, diz ele, não vivencia a natureza como paisagem, não conhece o nome das plantas e animais, não coleciona flores, borboletas ou cogumelos, não promove excursões escolares na "natureza", ou seja, não passeia. Ainda sobre esse aspecto discorre:

\footnotetext{
24 FLUSSER, Vilém. Fenomenologia do brasileiro: em busca de um novo homem, p. 63.

25 FLUSSER, Vilém. Fenomenologia do brasileiro: em busca de um novo homem, p. 63.

${ }^{26}$ FLUSSER, Vilém. Fenomenologia do brasileiro: em busca de um novo homem, p. 64 .
} 
Porque o amor pelas palmeiras e pelos sabiás, pelos prados e pelas flores, e em geral pelo berço esplêndido, não passa de subliteratura (descendente tardio e defasado de um romantismo francês que, ele próprio, já é pose), de uma subliteratura que faz parte da ideologia burguesa e ameaça transformar-se em chauvinismo (a parte paisagística do chauvinismo se chama, ultimamente, "tropicalismo"). Que se trata de subliteratura, prova-o a verdadeira literatura. $\mathrm{Na}$ maioria das vezes nem sequer contempla a natureza enquanto paisagem (por exemplo Machado de Assis, cujos romances se passam no Rio, nem sequer contempla o mar, a não ser para transformá-lo em palco de uma morte). A aparente grande exceção, Guimarães Rosa, prova a tese aqui defendida. Não canta ele a natureza enquanto paisagem, mas descreve pelo contrário como homem e natureza se fundem em todo místico, de maneira que plantas e animais passam a ser antropomorfos, e homens passam a ser animais e plantas. ${ }^{27}$

Flusser emite um juízo amargurado sobre a natureza brasileira, não a percebe exuberante, mas uma natureza traiçoeira e oposta ao homem nativo. Para ele, no caso brasileiro, a atitude estética perante a natureza não encontra espaço e é inapropriada. Na questão da agricultura a expressão "plantando dá" pode ser tomada como verdadeira, pois basta trabalhar o campo para fazer duas colheitas por ano. Porém, na ótica de Flusser, serão as últimas a se realizarem; é uma terra que se recusa a alimentar o homem e se estende por grande parte da superfície brasileira. Outro exemplo com conotação exagerada refere-se à floresta amazônica que revela na sua sombra um solo paupérrimo; "a atmosfera de estufa e a quantidade disponível de água possibilitam o crescimento e desenvolvimento de árvores gigantescas das madeiras mais nobres que formam

27 FLUSSER, Vilém. Fenomenologia do brasileiro: em busca de um novo homem, p. 65 . 
a floresta amazônica, mas não possibilitam praticamente outra flora, e a capa formada pela copa dos gigantes esconde o reino de sombra e morte." ${ }^{28}$

Também, salienta que o Nordeste durante o período de chuva sustenta milhões de pessoas, condenando-as à condição de miséria nos períodos de seca. Igualmente, as estepes do planalto que florescem durante poucas semanas para depois se tornarem arbustos mortos, a fim de "sustentar milhões de vacas magras" e "vaqueiros igualmente magros". Do mesmo modo, "os rios sulinos têm a falta de vergonha de correr todos em direção 'contrária', do oceano para o continente, não formando, portanto, artérias de transporte, como no resto do mundo, mas obstáculos ao transporte"29. Muitos outros exemplos poderiam ser aplicados, diz Flusser, pois a "natureza aqui é madrasta e o brasileiro é o enteado. A essência brasileira é incompreensível sem este aspecto." ${ }^{30}$ Entende que a maioria dos brasileiros tem dificuldades em compreender o verdadeiro caráter da natureza e, sobretudo, em vivenciá-la, inclusive o brasileiro culto que tem acesso a livros, jornais e viagens aos países desenvolvidos. O verdadeiro brasileiro é incapaz de odiar e invejar o outro, porque toda a sua energia e capacidade de ódio e ação está direcionada contra a natureza.

\section{CONSIDERAÇÕES FINAIS}

Não é preciso concordar com Flusser, pois é possível elencar inúmeros tópicos que pesam contra o filósofo ao explanar seu ponto de vista sobre a realidade brasileira. O que pretende com seu argumento é provocar um diálogo, uma conversação diante das múltiplas perspectivas. Por estar movido pela angústia e pela sensação de estar em um beco sem saída, "um pássaro fora do ninho", oferece um ponto de vista, uma nova visão sob o prisma do engajamento de um intelectual brasileiro imigrado da Europa.

\footnotetext{
28 FLUSSER, Vilém. Fenomenologia do brasileiro: em busca de um novo homem, p. 67.

29 FLUSSER, Vilém. Fenomenologia do brasileiro: em busca de um novo homem, p. 67.

30 FLUSSER, Vilém. Fenomenologia do brasileiro: em busca de um novo homem, p. 68.
} 
Gustavo Bernardo no prefácio da obra retrata muito bem a condição de Flusser no contexto brasileiro: "vê o Brasil, e o brasileiro, como um europeu que viveu entre nós por mais de 30 anos, portanto, não é europeu, e como um brasileiro que não nasceu nem morreu no Brasil, portanto não é brasileiro" ${ }^{31}$. Essa condição ambivalente o deixa em condições de observar o que naturalmente o brasileiro nato não consegue perceber, mesmo tendo exagerado no método de análise e, de certo modo, teve comprometida a sua análise fenomenológica.

Ao iniciar sua descrição fenomenológica sobre os habitantes e a natureza brasileira, afirmou que o depoimento procurava ser honesto. No entanto, o desespero e a desorientação diante da situação da realidade trágica da falta de engajamento do imigrante, pode ter contribuído para que Flusser tivesse uma impressão equivocada da realidade brasileira. Dá indícios de ser um sintoma de uma visão autocentrada em relação ao mundo.

O imigrante, para viver como homem livre, deve abrir sua "própria picada", dentro do seu mundo, em direção ao encontro consigo mesmo. Ser homem livre significa perceber sua própria situação de fora, projetar um mapa sobre ela e agir de acordo com o que dá sentido para transformar no mundo de sua vida. Flusser reconhece que esse esforço é um primeiro passo para encontra-se consigo mesmo. Todavia, é preciso transformar-se a fim de alterar o mundo e encontrar um significado para todos, pois a verdadeira maneira de ser brasileiro é a capacidade de sintetizar o amor ao próximo. Flusser tem certeza de que o brasileiro tem uma relação autêntica, sensível e cordial com o próximo e esses são motivos concretos para o "engajamento em prol desta terra". Reconhece que o novo homem que está emergindo dessa terra será o elemento importante para superar a crise da humanidade.

${ }^{31}$ FLUSSER, Vilém. Fenomenologia do brasileiro: em busca de um novo homem, p. 24. 


\section{REFERÊNCIAS}

BERNARDO, Gustavo; GULDIN, Rainer. O homem sem chão: a biografia de Vilém Flusser. São Paulo: Annablume, 2017. https://doi.org/10.1353/lbr.2011.0034 DOMINGUES, Ivan. Filosofia no Brasil: legados e perspectivas - Ensaios metafilosóficos. São Paulo: Editora Unesp, 2017. https://doi.org/10.1590/ 0100-512x2018n140150gj

FLUSSER, Vilém. Fenomenologia do brasileiro: em busca de um novo homem. Rio de Janeiro: Eduerj, 1998.

FLUSSER, Vilém. Ficções filosóficas. São Paulo: Editora da Universidade de São Paulo: 1998. https://doi.org/10.1590/s0103-06631998000400001

FLUSSER, Vilém. Da Religiosidade: a literatura e o senso de realidade. São Paulo: Escrituras Editora: 2002.

FLUSSER, Vilém. Bodenlos: uma autobiografia filosófica. São Paulo: Annablume, 2007.

FLUSSER, Vilém. Natural:mente: vários acessos ao significado de natureza. São Paulo: Annablume, 2011.

\section{ENDEREÇO CORRESPONDÊNCIA:}

Av. Ipiranga, 6681 - Partenon, Porto Alegre - RS, 90619-900 